\title{
OJS OPEN

\section{EXPERIÊNCIAS PEDAGÓGICAS ATRAVÉS DO PIBID: RELATOS E VIVÊNCIAS NO ENSINO DE GEOGRAFIA}

\author{
Mateus Pessetti ${ }^{1}$, Cristian Lino Gomes ${ }^{2}$ \\ ${ }^{1}$ Mestre em Geografia pela Universidade Federal de Santa Maria (UFSM). Professor de Geografia da rede privada \\ de escolas de Passo Fundo - RS. E-mail: mateuspessetti84@gmail.com - ORCID: http://orcid.org/0000-0001- \\ 9037-5153 \\ ${ }^{2}$ Graduado em Geografia pela Universidade de Passo Fundo (UPF). Professor de Geografia da rede pública do Rio \\ Grande do Sul. E-mail: cristianlino18@ hotmail.com - ORCID: http://orcid.org/0000-0003-1926-1721
}

Artigo recebido em 15/08/2020 e aceito em 24/12/2020

\begin{abstract}
RESUMO: O presente artigo apresenta uma reflexão e um relato a partir das vivências e práticas experienciadas por meio do Programa Institucional de Bolsas de Iniciação à Docência - PIBID. Para tanto, realizou-se uma breve discussão teórica a respeito do ensino de geografia e da cartografia escolar. Posteriormente, realizou-se o relato de duas práticas desenvolvidas junto a estudantes de uma escola de ensino fundamental no município de Passo Fundo/RS, onde encontra-se inserido o subprojeto PIBID - Geografia da Universidade de Passo Fundo. O incremento do PIBID nas instituições formadoras de professores, oportuniza aproximação entre o saber acadêmico e o escolar. É necessário oportunizar meios para que o conhecimento produzido dentro destas instituições esteja em consonância com a sociedade, especialmente com o meio escolar se tratando da formação de professores. Além de evidenciar a importância que o PIBID possui para a formação de professores, evidenciou-se a necessidade de práticas adequadas para uma efetiva alfabetização cartográfica, desenvolvendo assim habilidades de orientação, localização e a decodificação da linguagem cartográfica.
\end{abstract}

Palavras-chave: Ensino de Geografia; PIBID; Práticas pedagógicas; Cartografia escolar.

\section{PEDAGOGICAL EXPERIENCES THROUGH PIBID: REPORTS AND EXPERIENCES IN TEACHING GEOGRAPHY}

\begin{abstract}
This article presents a reflection and a report from the experiences and practices experienced through the Institutional Program for Teaching Initiation Scholarships - PIBID. To this end, a brief theoretical discussion was held regarding the teaching of geography and school cartography. Subsequently, two practices developed with students from an elementary school in the city of Passo Fundo / RS were reported, where the subproject PIBID - Geography of the University of Passo Fundo is inserted. The increase in PIBID in teacher training institutions, provides an opportunity to bring academic and school knowledge closer together. It is necessary to provide opportunities for the knowledge produced within these institutions to be in line with society, especially with the school environment when it comes to teacher training. In addition to highlighting the importance that PIBID has for teacher training, the need for adequate practices for effective cartographic literacy was highlighted, thus developing skills in orientation, localization and the decoding of cartographic language.
\end{abstract}

Keywords: Geography teaching; PIBID; Pedagogical practices; School cartography. 


\section{INTRODUÇÃO}

O presente texto consiste em um relato a partir de algumas experiências vivenciadas por meio do Programa Institucional de Bolsas de Iniciação à Docência - PIBID. Dentre os objetivos estabelecidos pelo programa, destacamos dois, os quais estão centrados na valorização da docência na educação básica, bem como a contribuição para a articulação entre teoria e prática, necessárias à formação de professores. Por meio do desenvolvimento de atividades desta natureza, busca-se elevar a qualidade das ações acadêmicas nos cursos de licenciatura e, logo, o aperfeiçoamento dos futuros professores.

Nas palavras de Darroz, Betencourt e Valério (2018), o PIBID tem favorecido para a inserção dos acadêmicos dos cursos de licenciaturas, oportunizando o desenvolvimento de atividades pedagógicas junto a escolas da educação básica públicas. Os autores mencionados (2018, p. 21) complementam, afirmando que:

Um dos mais importantes valores deste Programa é, sem dúvida, a aproximação do docente em formação - inicial e continuada - com a vida da escola. [...] . É esse - ou pelo menos deveria ser - o laboratório da experiência do professor. É desse lugar complexo que brotam as necessidades que provocam experiências capazes de produzir as mudanças.

O incremento do PIBID nas instituições formadoras de professores, oportuniza a aproximação entre o saber acadêmico e o escolar. É necessário oportunizar meios para que os conhecimentos produzidos dentro das instituições, estejam em consonância com as mudanças na estrutura social, as quais se manifestam cotidianamente na organização da comunidade escolar.

Neste aspecto, salienta-se Moreira (2014, p. 151), onde infere que:

O currículo universitário e a grade escolar são uma relação de espelho. O cotidiano da universidade e o cotidiano da escola, porém, são distintos. E mais distintos ainda os modos de relacionamento respectivos com a sociedade. (...) É solto na universidade e integrado na escola. É disseminado na universidade e tem que ser interligado na escola.

Diante da constatação feita por Moreira (2014), destaca-se que as atividades desenvolvidas junto aos educandários, oportunizam a aproximação entre universidade e escola. Sendo assim, uma das maneiras de construir o conhecimento escolar, é o estabelecimento de estratégias para o processo de ensino-aprendizagem, melhorando qualitativamente a práxis de graduandos, professores e orientandos.

Partindo de tais considerações, objetivou-se apresentar e discutir a respeito de duas práticas pedagógicas realizadas com turmas de $6^{\circ}$ e $8^{\circ}$ ano, em uma escola da rede pública 
municipal de Passo Fundo/RS, na disciplina de Geografia. Ressalta-se que ambas as atividades tiveram como tema central questões inerentes a cartografia. Para tanto, organizou-se o texto em três momentos: (1) revisão bibliográfica, onde buscou-se discutir teoricamente os conceitos centrais da pesquisa, como a cartografia escolar; (2) relato das atividades, destacando os recursos didáticas utilizados e as etapas; e, (3) análise e reflexão da práxis pedagógica.

Além de evidenciar a importância que o PIBID possui para a formação de professores, evidenciou-se a necessidade de práticas pedagógicas para uma efetiva alfabetização cartográfica, desenvolvendo assim habilidades de orientação, localização e a decodificação da linguagem cartográfica.

\section{ENSINO DE GEOGRAFIA E CARTOGRAFIA ESCOLAR}

Neste fragmento do texto, busca-se realizar uma breve reflexão a respeito do ensino de geografia e do uso da cartografia escolar no processo de ensino-aprendizagem. Nosso propósito, consiste em apresentar uma discussão teórica, levantando algumas questões que possam legitimar e justificar o desenvolvimento das práticas aqui relatadas.

Construir o conhecimento geográfico em sala de aula, é uma oportunidade que possibilita ao estudante a compreensão do mundo em que vive, visto que o olhar geográfico aborda as distintas ações humanas nas sociedades distribuídas na superfície terrestre. Uma das habilidades inerentes ao ensino de geografia, refere-se ao desenvolvimento da percepção espacial, apreendendo a distribuição dos fenômenos geográficos. Ademais, uma das ferramentas para o estabelecimento desta habilidade, consiste no uso da linguagem cartográfica, ou seja, a utilização de mapas e a decodificação de suas atribuições. (BASE NACIONAL COMUM CURRICULAR, 2018).

A utilização de recursos cartográficos para apreender a espacialidade dos fenômenos geográficos, se tornou uma das marcas da geografia escolar e acadêmica. Na contemporaneidade, difícil é pensar em geografia, sem associá-la aos mapas. Neste contexto, destacamos Baptista (2019, p. 54) onde afirma que:

Os mapas e as representações espaciais, portanto, sempre foram muito importantes a Geografia, tanto que, muitas vezes, se tornaram o símbolo da área do conhecimento. $\mathrm{Na} \mathrm{BNCC}$, os elementos cartográficos, estão apontados como formas essenciais e indispensáveis à educação geográfica, ampliando assim, a necessidade de se desenvolver metodologias de ensino capazes de contribuir com a inserção desses elementos na disciplina escolar.

A utilização de metodologias para o desenvolvimento de habilidades cartográficas, permite reconhecer espacialmente a distribuição dos fenômenos geográficos, sejam eles de 
ordem social e/ou ambiental. Entretanto, um dos grandes desafios enfrentados pelos professores de geografia consiste no desenvolvimento e construção de metodologias que possam viabilizar o processo de ensino-aprendizagem, especialmente em conteúdos marcados pela complexidade, como a cartografia.

Ponthuska (2009), por meio de pesquisas realizadas junto a escolas públicas e privadas do Rio de Janeiro, concluiu que existe um grande déficit nos alunos do ensino médio na interpretação de representações cartográficas utilizadas pelos professores. A autora destacou que em alguns casos, o ensino de geografia fica restrito ao uso demasiado do livro didático, sem uma abordagem que considere aspectos relacionados ao espaço de vivência dos estudantes.

Almeida (2010, p. 77) ressalta que “[...] na vida moderna, é cada dia mais notória e importante a utilização de mapas". Para que não haja esse analfabetismo cartográfico no ensino médio, é necessário que a linguagem cartográfica seja um tema excepcionalmente abordado no ensino fundamental, possibilitando desenvolver gradualmente as habilidades inerentes a cartografia e a geografia.

Devemos considerar que o estudo da cartografia na geografia, por vezes, se mostra como uma das maiores dificuldades apresentadas pelos estudantes. Os conteúdos inerentes a linguagem cartográfica demonstram certa abstração, aspectos que devem ser considerados pelos professores ao trabalharem com a temática. É necessário, pois, desenvolver uma alfabetização cartográfica, por meio de práticas que possibilitem concretizar a abstração que caracteriza o conteúdo em questão.

Para Passini (2012), o objetivo da alfabetização cartográfica é o avanço da leitura de representações em diferentes níveis dos elementos espacializados. Conforme Santos (2014, p. 21), “[...] o aluno adquire seus conhecimentos ao longo dos anos de experiência escolar, caracterizando gradualmente um processo de assimilação sistemática, e no final, o aluno estará alfabetizado cartograficamente".

Portanto, o uso de recursos cartográficos e a utilização de representações, deveria perpassar por todas as discussões inerentes a geografia. Percebe-se que o estudo da linguagem cartográfica fica restrito as séries do ensino fundamental, sendo esquecida com o passar dos anos, o que culmina em dificuldades na análise e interpretação de mapas em etapas no ensino médio, onde exige-se mais grau de compreensão.

Corroborando com a discussão, evidenciamos Castrogiovanni (2006, p. 30) onde afirma que: 
Quando falamos em alfabetizar nos referimos à interpretação de símbolos, que posteriormente permitirão a relação a aplicabilidade em outras dimensões. Assim, podemos transferir o processo de alfabetização aos símbolos cartográficos e etapas temporais, que oportunizam ao aluno a aplicabilidade posterior em leituras de mapas e contextos espaço-temporais.

Ao discutir sobre o mesmo tema, Rizzatti (2018, p. 58) evidencia que:

A alfabetização cartográfica refere-se as habilidades de leitura e interpretação de documentos com representação gráfica, sejam eles mapas, cartas ou plantas. Porém, a leitura de mapas não pode ser entendida apenas como uma técnica, mas capaz de fornecer aptidões para localização, descrição e opinião sobre o fenômeno observado.

A partir da Base Nacional Comum Curricular (2018), as abordagens relacionadas ao estudo da cartografia estão concentradas, majoritariamente no $6^{\circ}$ ano do Ensino Fundamental, onde os estudantes apreendem sobre a linguagem cartográfica e tipos de representações, muito embora a cartografia permeia diferentes temas e níveis de ensino. Ressaltamos Almeida (2014) que evidencia sobre o equívoco cometido em livros didáticos quando concentra-se o estudo da cartografia e um único ano do programa curricular, como se a cartografia estivesse desvinculada com os outros conteúdos da geografia.

Diante das considerações feitas, é possível perceber a necessidade de perceber os mapas como ferramenta que viabiliza a construção do conhecimento geográfico entre professores e alunos. O desenvolvimento de habilidades cartográficas só será possível diante do estabelecimento de metodologias adequadas e busquem evidenciar a importância dos recursos cartográficos para o entendimento dos fenômenos geográficos.

\section{PRÁtICAS E VIVÊNCIAS NO ENSINO DE GEOGRAFIA: A CARTOGRAFIA ESCOLAR}

A partir das considerações teóricas feitas, busca-se descrever a refletir a partir das práticas pedagógicas desenvolvidas junto a alunos de uma escola municipal de Passo Fundo/RS.

Cartografando o espaço da escola, $6^{\circ}$ ano

Através desta metodologia, teve-se como objetivo trabalhar de forma prática aspectos inerentes a orientação e localização no espaço geográfico. De modo especial, foram abordados os seguintes temas: pontos cardeais e colaterais, meios de orientação (bússola, rosa-dos-ventos, sol), manuseio de mapas e escala geográfica. 
Para tanto, foi necessário que a professora titular das turmas, abordasse os temas na aula que antecedeu a prática, dando condições teóricas para que os estudantes pudessem desenvolvê-la. Também, foi solicitado para que cada estudante elaborasse a sua rosa-dosventos, a qual foi utilizada durante a realização da atividade.

Foram produzidos 20 envelopes, os quais estavam distribuídas nos arredores da escola. Dentro deles haviam informações e passos que norteavam a continuidade da prática. A turma foi dividida em 4 grupos, cada qual identificado com uma cor: verde, vermelho, azul e amarelo. Ao todo, cada grupo possuía 5 envelopes.

O conteúdo que fazia parte dos envelopes estava organizado em 5 cartelas, as quais correspondiam aos 5 passos da dinâmica. Os alunos deveriam seguir a ordem numérica e realizar as solicitações de cada uma das etapas. Correspondiam as etapas:

$\underline{\text { Etapa } 1}$ - Uma cartela contendo 4 indicações que orientavam a sequência entre um ponto e outro. Ex.: Caminhe 5 passos na direção do "nascer do Sol”. (Figura 1).

FIGURA 1 - CARTELA CORRESPONDENTE A ETAPA 1

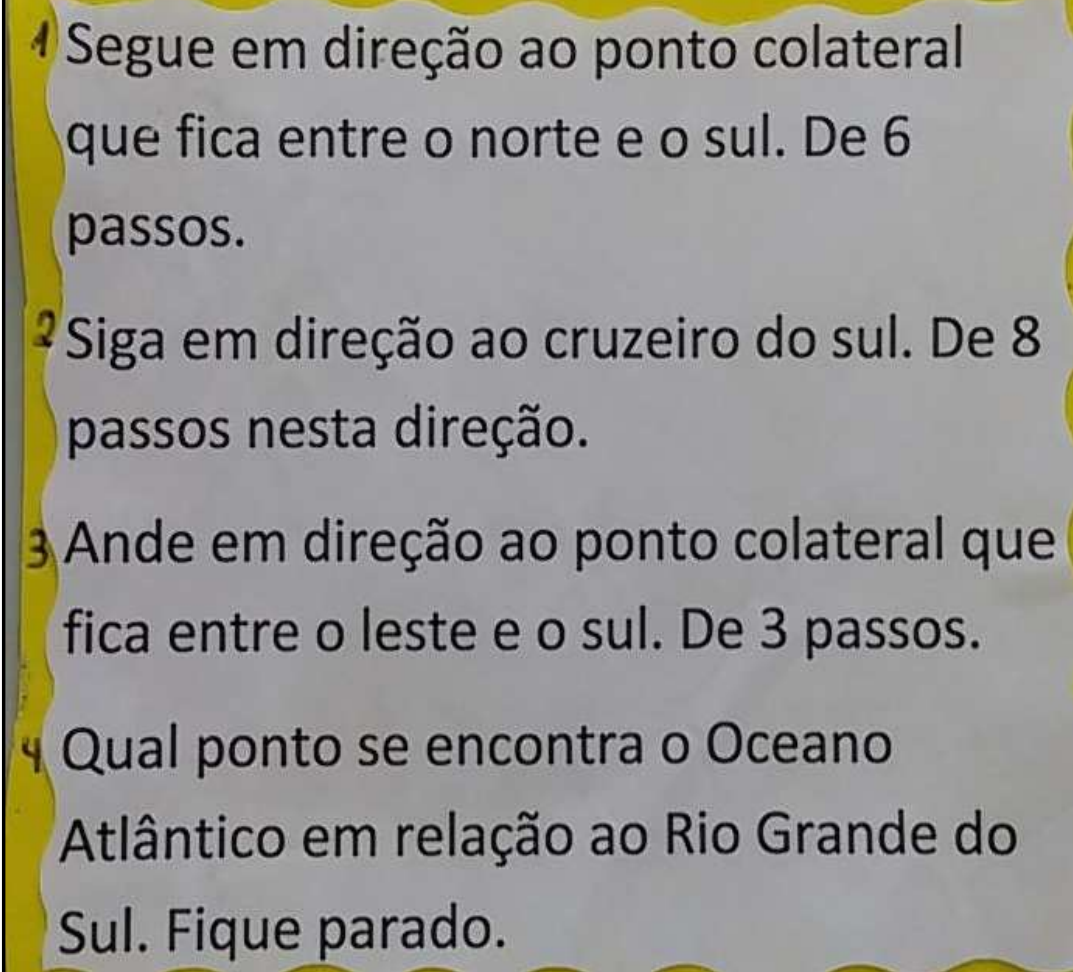

Fonte: Acervo pessoal, 2017. 
Etapa 2 - Interpretação de um croqui do espaço urbano, onde os educandos necessitavam manter uma relação entre a escola localizada no mapa, com outros pontos de referência destacados. Ex.: A posição da escola em relação ao hospital. (Figura 2)

FIGURA 2 - CROQUI DA ESCOLA, CORRESPONDENTE A ETAPA 2

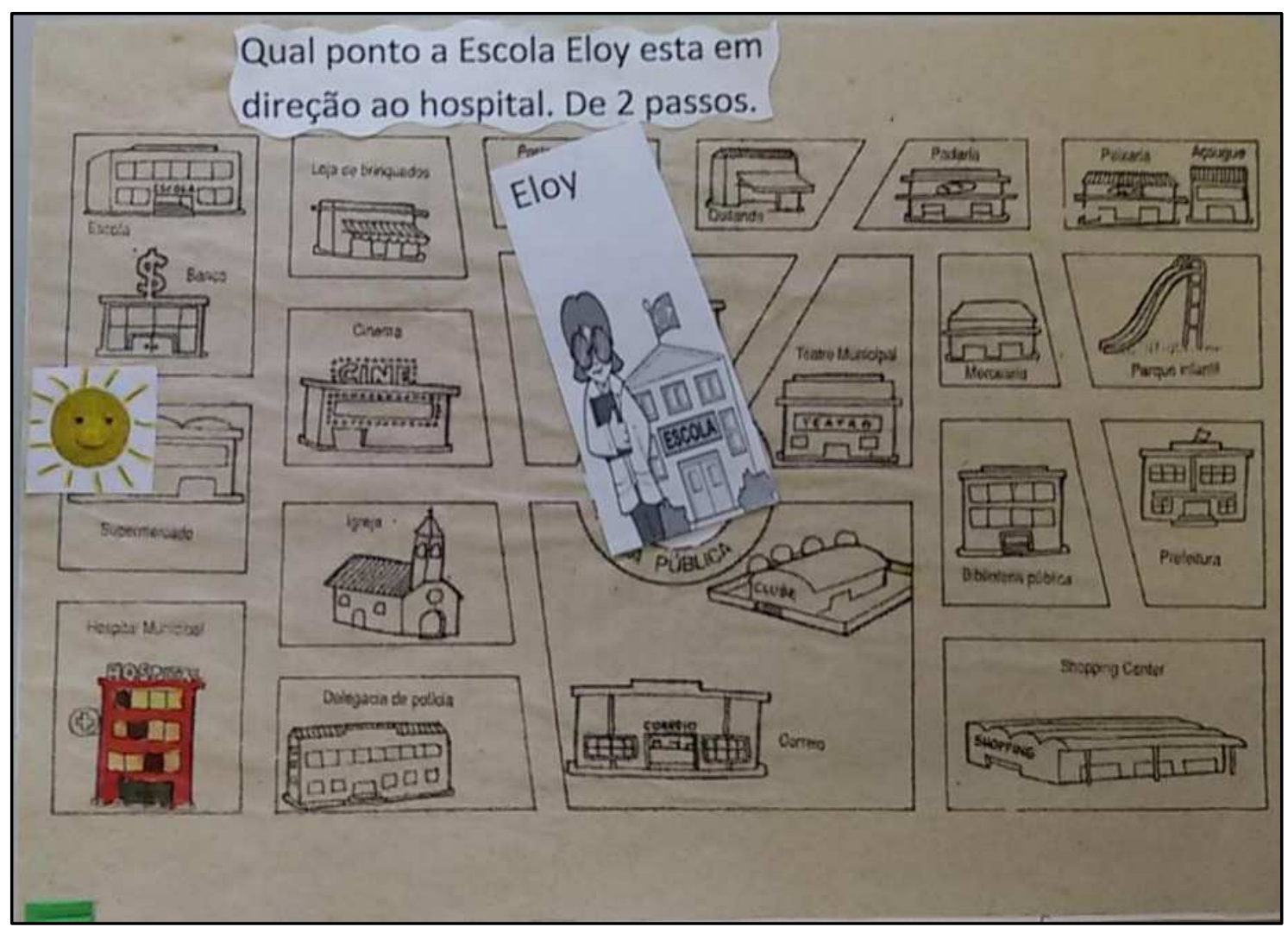

Fonte: Acervo pessoal, 2017.

Etapa 3 - Interpretando o mapa do Brasil, os alunos deveriam inferir, a partir da leitura cartográfica e norteada pela rosa dos ventos, a posição do território do Rio Grande do Sul em relação aos demais Estados nacionais. Ex.: A posição do Rio Grande do Sul em relação ao Acre. (Figura 3). 
FIGURA 3 - MAPA DO BRASIL E A POSIÇÃO DO RIO GRANDE DO SUL, CORRESPONDENTE A ETAPA 3

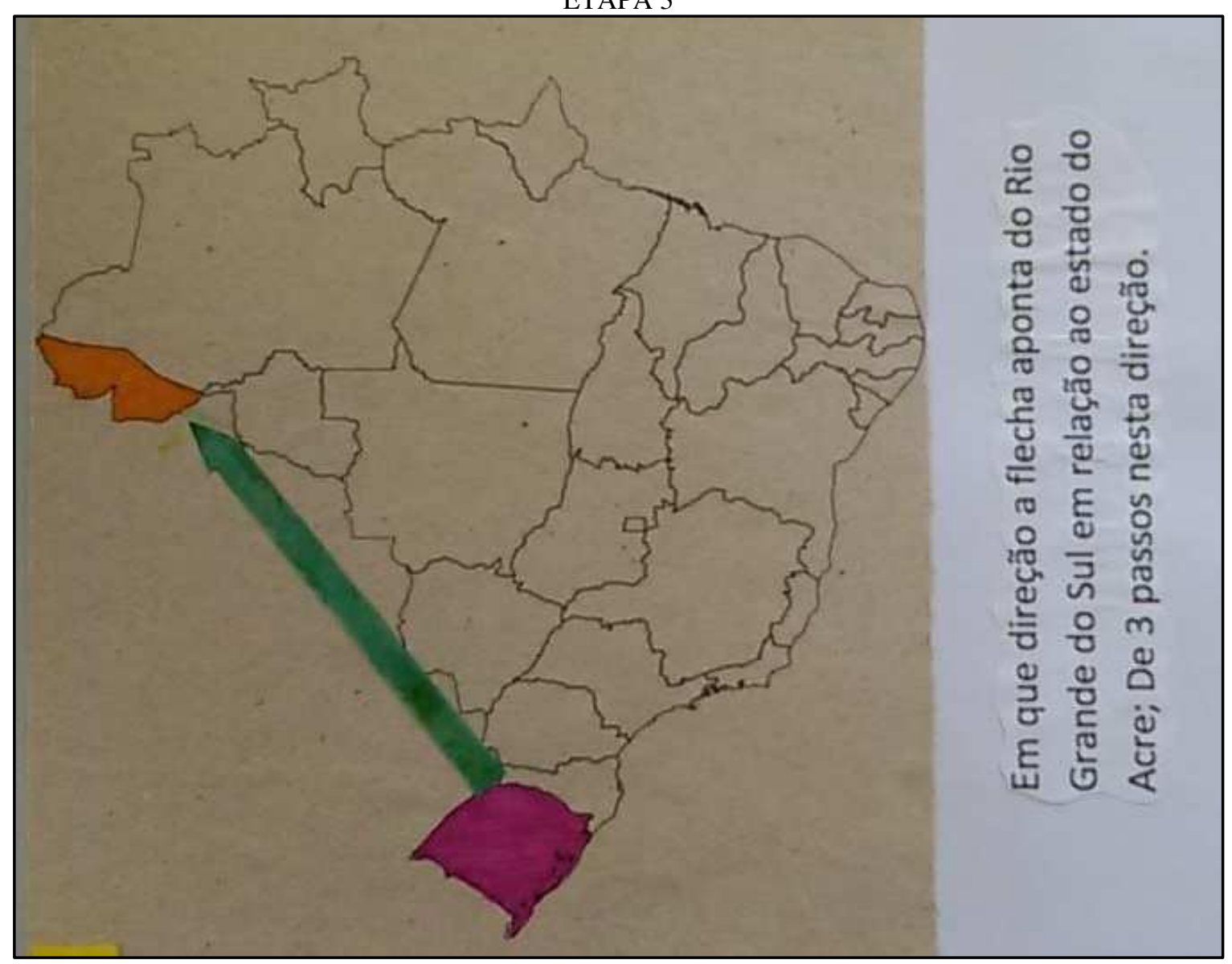

Fonte: Acervo pessoal, 2017.

Etapa 4 - Foram escolhidos 4 locais nas redondezas da escola, assim, novamente, os alunos deveriam manter relações entre a escola e o referido ponto. Ex.: A posição da UPF em relação a Escola. (Figura 4)

Etapa 5 - A posição da Escola em relação à municípios próximos de Passo Fundo/RS. Ex.: A escola em relação ao município de Soledade/RS. (Figura 5) 
FIGURA 4 - A ESCOLA EM RELAÇÃO A OUTROS PONTOS DA CIDADE DE PASSO FUNDO/RS

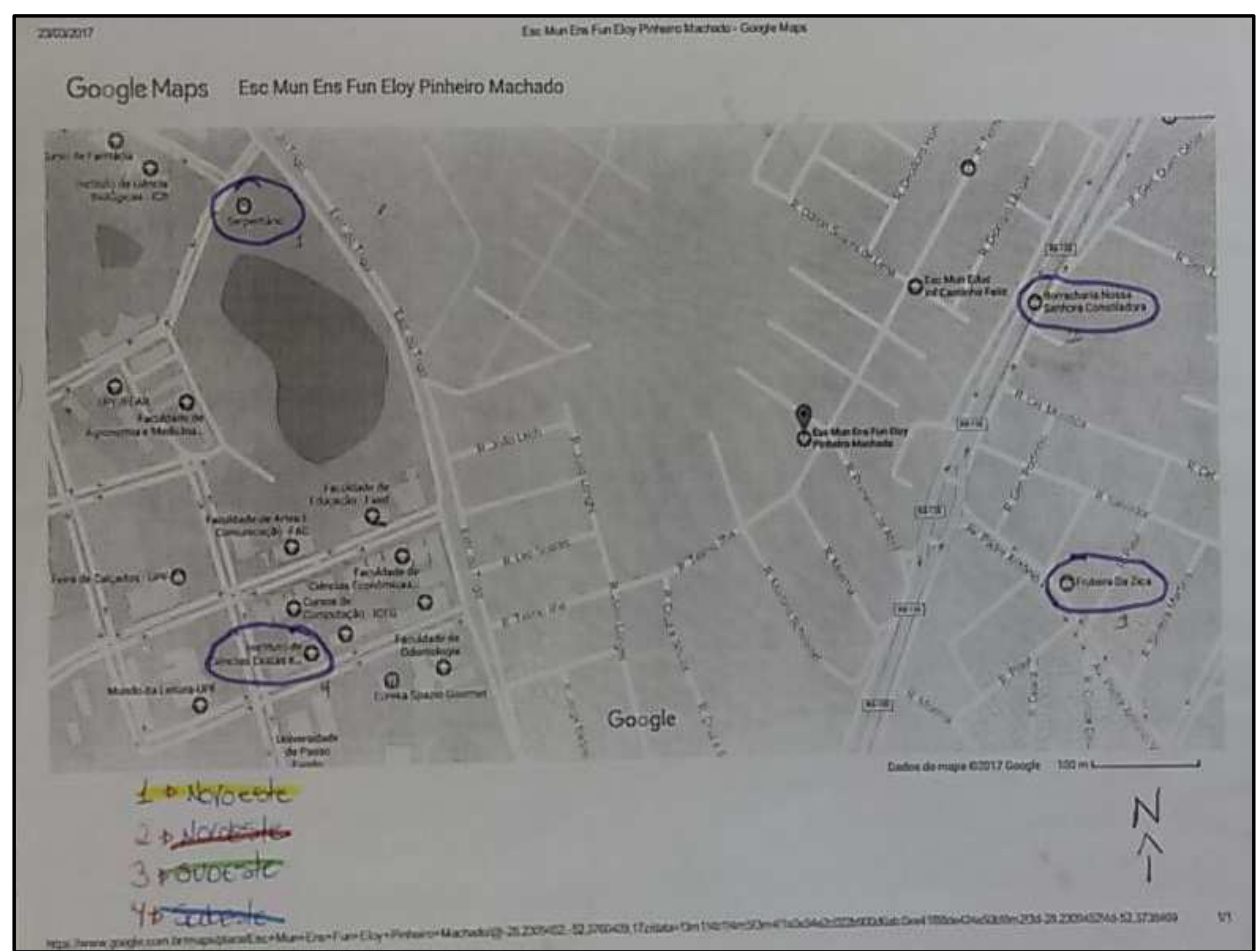

Fonte: Acervo pessoal, 2017.

FIGURA 5 - A ESCOLA EM RELAÇÃO A OUTROS MUNICÍPIOS VIZINHOS DE PASSO FUNDO/RS

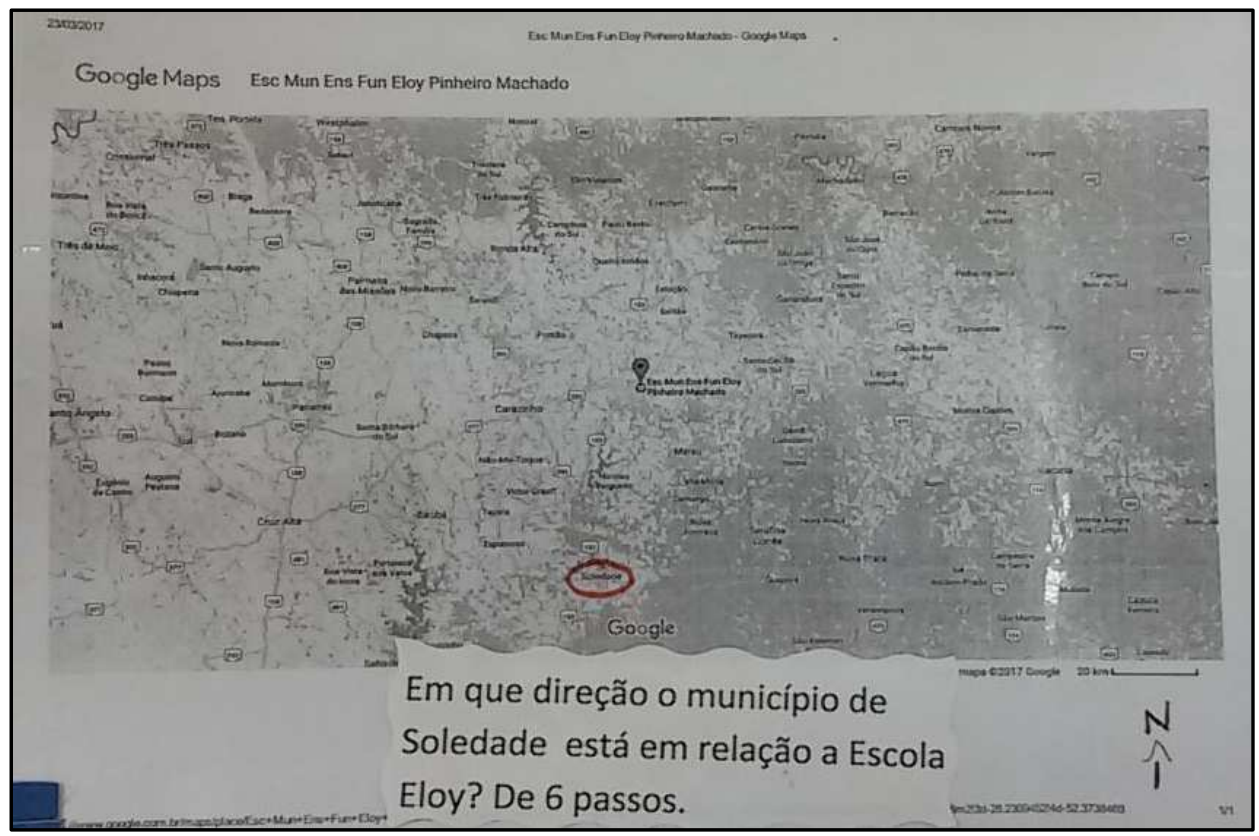

Fonte: Acervo pessoal, 2017. 


\section{Descrevendo a prática}

Diante das observações nas aulas que eram realizadas semanalmente, foi constatado que era necessário desenvolver algo que exigisse maior concentração, visto que as turmas apresentavam a facilidade de dispersão como uma de suas principais características. Então, foi preciso a ajuda de outros bolsistas do PIBID e da supervisora.

Para o início da atividade, realizou-se a divisão dos grupos e a distribuição dos envelopes. Cada grupo de estudante, estava acompanhado de um pibidiano ou de um professor. Destaca-se que cada grupo foi posicionado em um ponto diferente. A partir da colocação dos grupos em seus respectivos lugares, o grupo deveria iniciar a atividade, seguindo as orientações dadas na etapa 1, conforme demonstrado na Figura 1.

A cada nova parada, uma nova etapa era proposta aos estudantes, onde deveriam ler atentamente as orientações e realizar as solicitações. Ao final da atividade, os alunos deveriam desenhar o caminho percorrido em uma folha que acompanhava o grupo. $\mathrm{O}$ traçado do caminho realizado pelos estudantes deveria estar de acordo com a proposta dos pibidianos. A conferência da atividade aconteceu em sala de aula, onde os bolsistas traçaram no quadro os quatro caminhos percorridos pelos grupos.

Conforme previsto no planejamento, a atividade exigiu concentração e conhecimento teórico da linguagem cartográfica, possibilitando assim a integração entre os estudantes que compunham os grupos. Além de desenvolver habilidades inerentes ao conhecimento geográfico, o fato de a prática ter sido realizada em grupo, corroborou para as trocas e o aumento das relações entre os estudantes, assim como, dos bolsistas pibidianos para com o ambiente escolar.

Ao final da realização da atividade, foi possível perceber o envolvimento e estimulação dos estudantes na realização da prática. Embora tenha se realizado nos arredores da escola, permitiu que os estudantes não estejam limitados as paredes da sala de aula para a efetivação de seu aprendizado. Importante destacar que foram considerados aspectos relacionados a escola enquanto ponto de referência para a sequência da prática, o que oportuniza uma aprendizagem significativa e que está vinculada ao cotidiano da turma, visto que este também é um dos propósitos da geografia trabalhada no $6^{\circ}$ ano. 
Compreendendo o Espaço Geográfico Americano, $8^{\circ}$ ano

Um dos conteúdos trabalhados pelos professores no $8^{\circ}$ ano do Ensino Fundamental, consiste na compreensão do espaço geográfico do continente americano. A partir da BNCC (2018) os conteúdos programados para esta etapa buscam analisar as ações humanas e suas consequências em diferentes espaços e tempos, identificando os países em desenvolvimento e subdesenvolvidos, em seus diferentes aspectos e formas de regionalização, avaliando criticamente o processo de formação dessas sociedades, com ênfase ao continente americano e africano.

Tinha-se como desafio elaborar algo prático, que oportunizasse a aplicação da teoria estudada em sala de aula. Além de serem considerados os conteúdos trabalhados pelos estudantes, levou-se em conta o potencial cognitivo da turma, para que pudessem ser estabelecidas estratégias que viabilizassem a compreensão dos temas.

Por meio da realização da atividade, teve-se como objetivo identificar as particularidades do espaço geográfico americano; conhecer e localizar os países pertencentes a América; e, aplicar os conhecimentos adquiridos nas aulas teóricas. O exercício esteve subsidiado nos seguintes temas: países e suas capitais, formas de governo, população, clima, idioma, indicadores sociais e econômicos.

Para início da atividade, era necessário um mapa do continente americano, o qual foi retirado e colado em uma superfície de isopor, sendo assim, possível a fixação das bandeiras nos seus referidos países. (FIGURA 6). Foram selecionados 32 países, cada um destes com suas respectivas cartelas, evidenciando características sociais, econômicas e ambientais. (FIGURA 7). 


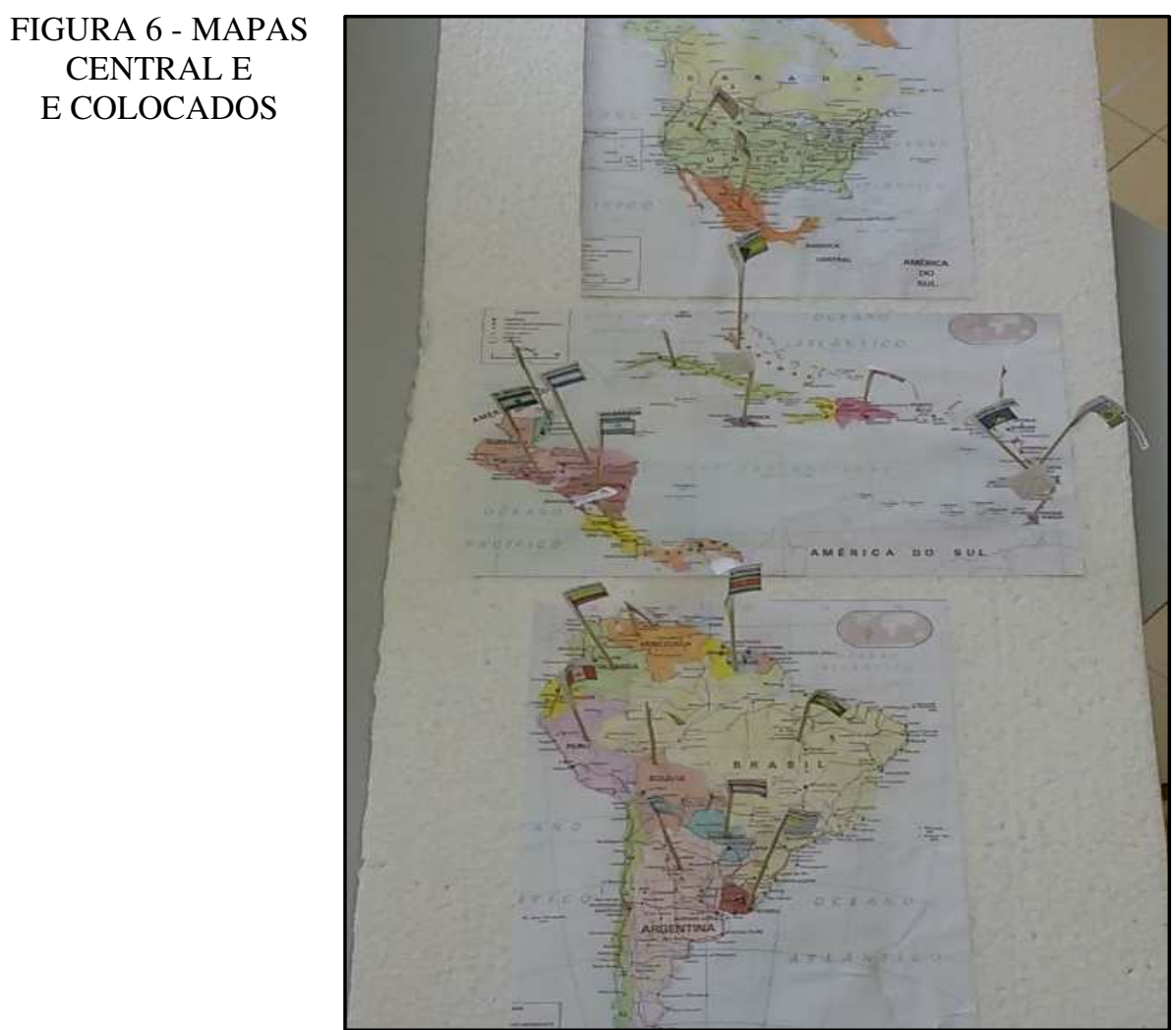

DA AMÉRICA DO SUL, NORTE RECORTADOS SOBRE O ISOPOR

Fonte: Acervo pessoal, 2017.

FIGURA 7 - CARTELAS UTILIZADAS NA ATIVIDADE COM AS INFORMAÇÕES DE CADA PAÍS

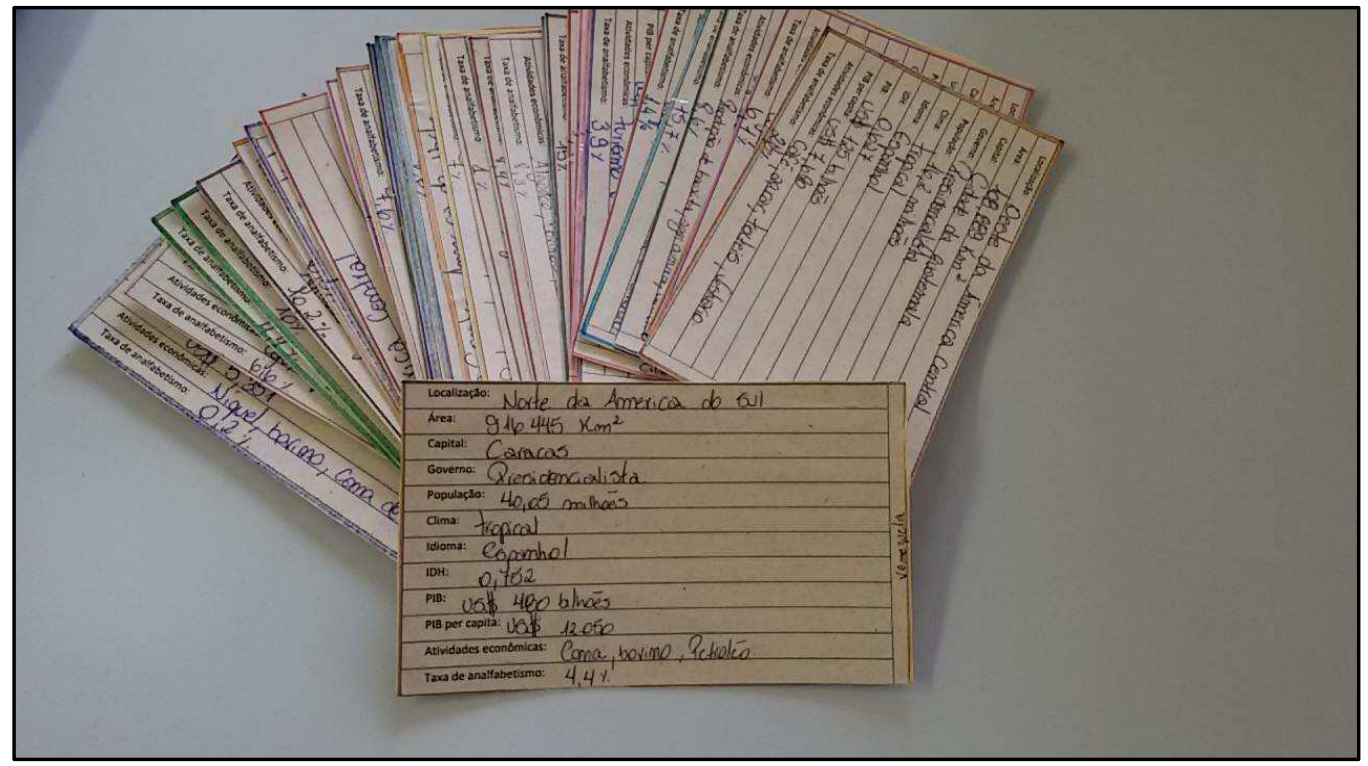

Fonte: Acervo pessoal, 2017. 
Para a localização dos países, foram confeccionadas bandeiras correspondentes a cada um dos países (FIGURA 8). Após as perguntas, as mesmas deveriam ser fixadas nos seus respectivos países para indicar a localização.

FIGURA 8 - BANDEIRAS DE CADA PAÍS EM PALITOS PARA SEREM FIXADAS NOS MAPAS SOBRE O ISOPOR

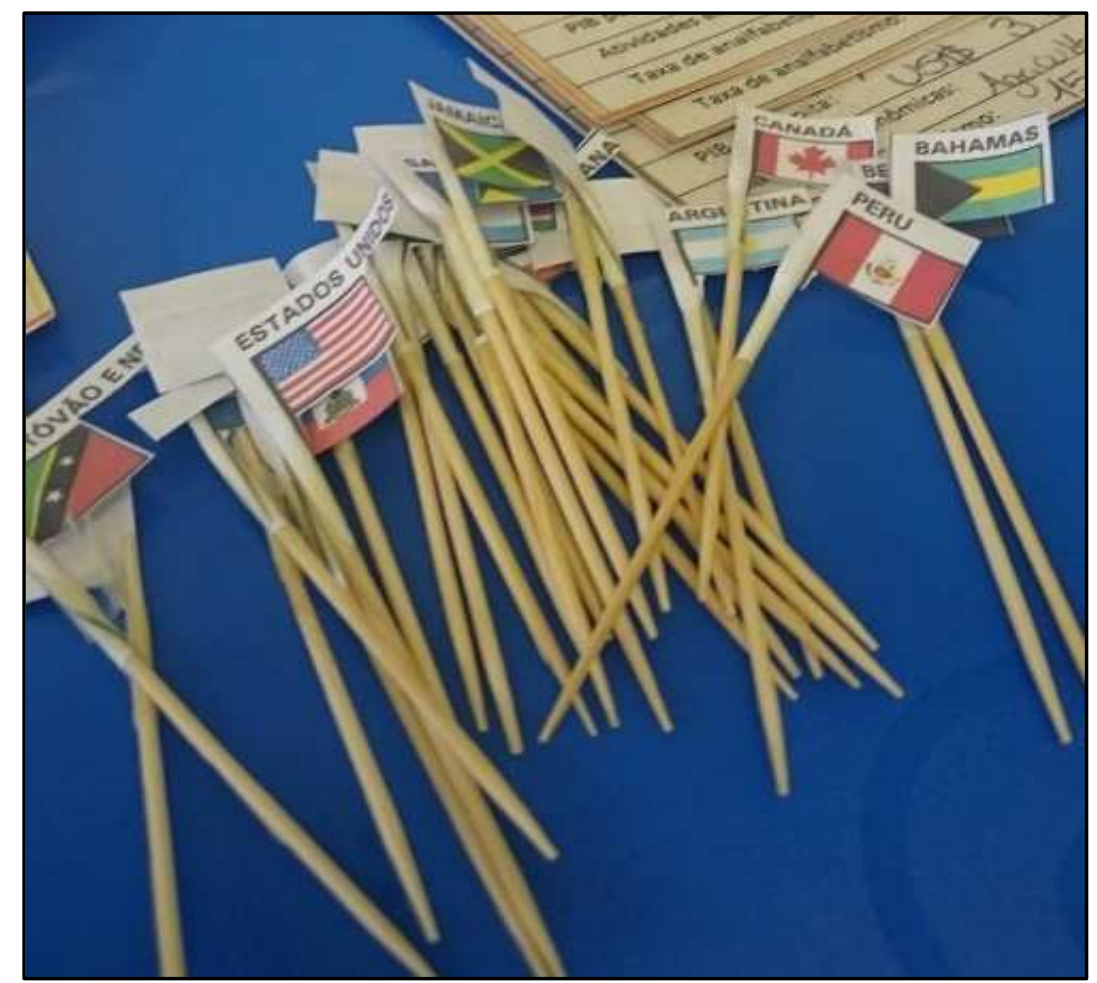

Fonte: Acervo pessoal, 2017.

Descrevendo a prática

Inicialmente, as turmas foram organizadas em 4 grandes grupos, os quais possuíam o kit completo da atividade (mapa no isopor, cartelas e bandeiras). (FIGURA 10). A interação entre os estudantes acontecia entre os componentes de cada grupo.

O seguimento da atividade se dava da seguinte maneira: cada estudante tinha como possibilidade a escolha de quatro características (capital, população, clima e idioma, por exemplo) para questionar o seu colega. A partir da apresentação das características solicitadas, os estudantes deveriam adivinhar e localizar no mapa da América o referido país, indicando o mesmo com a ajuda da bandeira. Com o término das cartelas, ocorria um rodízio entre os grupos, onde eram compartilhadas cartelas de outros países, para que todos os grupos pudessem ter a oportunidade de ter contato com os 32 países selecionados. 
FIGURA 10 - MATERIAL COMPLETO DO JOGO

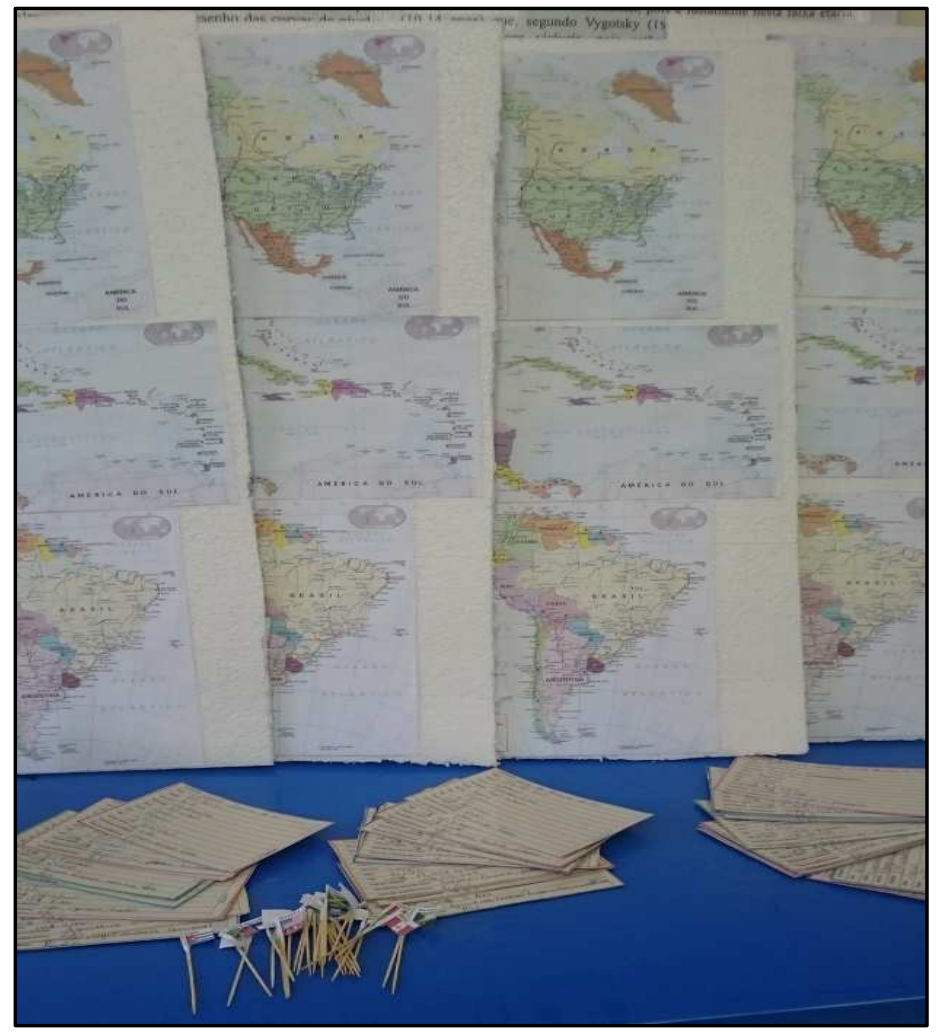

Fonte: Acervo pessoal, 2017

É importante salientar que a turma possuía alunos especiais, e, portanto, a atividade teve que ser adaptada para que estes pudessem participar. Aos referidos estudantes ficou a tarefa de apenas localizar os países da América, sem levar em consideração as informações das cartelas. A atividade tinha término quando toda a turma havia contemplado todos os países e suas respectivas características.

Destaca-se que, em função da natureza dessa atividade ser um "Quiz" de perguntas e respostas aplicadas a localização no mapa, ela foi pensada para o encerramento do conteúdo, ou seja, o término das discussões inerentes a geografia do continente americano. Devido a sua flexibilidade, a prática pode ser apresentada e adaptada para diferentes temáticas geográficas.

Ao longo do desenvolvimento da prática, percebeu-se que a grande maioria dos estudantes se envolveu de maneira efetiva, o que nos leva a destacar a potencialidade demonstrada pela atividade. Ressalta-se que, os conteúdos abordados durante o $8^{\circ}$ ano do Ensino Fundamental, por vezes, apresentam-se de maneira mais teórica, todavia podendo serem trabalhados com o uso de jogos de perguntas e respostas, elaboração de maquetes e mapas temáticos, atividades de natureza mais concreta, que de certo modo envolvam os estudantes e possam corroborar para o processo de ensino-aprendizagem. 


\section{CONSIDERAÇÕES FINAIS}

O propósito deste trabalho se estabeleceu na apresentação de metodologias alternativas para o trabalho de conteúdos da geografia no ensino fundamental, de modo especial às questões inerentes a cartografia, considerando que este campo do conhecimento permite apurar a percepção da organização do espaço geográfico, desenvolvendo habilidades relacionadas a compreensão, interpretação e elaboração de mapas.

Possibilitar aos estudantes metodologias diferenciadas com o uso de mapas, oportuniza entender a espacialidade de diferentes fenômenos geográficos, podendo ser o início de uma análise crítica, estabelecendo-se relações com outros aspectos importantes da sociedade e da natureza. Neste aspecto, destacamos a atividade desenvolvida com o $8^{\circ}$ ano que, acima de possibilitar a compreensão da localização dos diferentes países que compõem a América, oportunizou entendê-los a partir de suas características sociais, econômicas, políticas e ambientais.

Especialmente considerando a atividade desenvolvida com os alunos do $6^{\circ}$ ano, a cartografia em sua natureza apresenta certa complexidade. Portanto, é necessário possibilitar a construção do conhecimento geográfico a partir da concreticidade, instigando os estudantes a aplicarem e decodificarem a linguagem cartográfica, habilidades que foram trabalhadas na prática relatada. Além de que, pode-se situar o espaço escolar em relação a outros, evidenciando que o espaço de vivência dos estudantes está inserido em um contexto.

Deve-se destacar que as referidas práticas só puderam ser desenvolvidas a partir de um trabalho efetivo entre professores, bolsistas e alunos da escola, o que evidenciou a importância que o Programa Institucional de Bolsas de Iniciação à Docência - PIBID possui na formação inicial de professores.

\section{REFERÊNCIAS}

ALMEIDA, R. D. de. Do Desenho ao Mapa: Iniciação Cartográfica na Escola. 4. ed. São Paulo: Contexto, 2010.

ALMEIDA, R. D.; ALMEIDA, R. A. Fundamentos e perspectivas da cartografia escolar no Brasil. Revista Brasileira de Cartografia, Rio de Janeiro, N0 63/4, p. 885-897, Jul/Ago/2014

BAPTISTA, N. L. Cartografia escolar, multimodalidade e multiletramentos para o ensino de geografia na contemporaneidade. Programa de Pós-graduação em Geografia da 
Universidade Federal de Santa Maria. Tese de Doutorado (Doutorado em Geografia), Santa Maria, 2019

BRASIL. Ministério da Educação. Base Nacional Comum Curricular - Ensino Fundamental. Brasília, 2018.

CASTROGIOVANI, A. C. Brincar e cartografar com os diferentes mundos geográficos: a alfabetização espacial. 1 ed. Porto Alegre: Editora PUC-RS, 2006.

DARROZ, L. M.; BETENCOURT, M. de F. B.; VALÉRIO, P. da S. Saberes e experiências em construção: a importância do PIBID. Curitiba: CRV, 2018.

PASSINI, E. Y. Reflexões metodológicas e cognitivas: aproximações entre sujeito e objeto In: Alfabetização cartográfica e aprendizagem de geografia. 1.ed. São Paulo: Cortez, 2012. p. 23-43.

MOREIRA, R. O discurso do avesso: para a crítica da geografia que se ensina. São Paulo: Contexto, 2014.

PONTUSCHKA, N. N.; PAGANELli, T. L.; CACETE, N. H. Para ensinar e aprender Geografia. 3. Ed. São Paulo: Cortez, 2009.

PREFEITURA MUNICIPAL DE PASSO FUNDO. Parâmetros Curriculares de Passo Fundo/RS, p. 195 - 204, 2008.

RIZZATTI, M. A cartografia escolar e as inteligências múltiplas no ensino de geografia: contribuições das geotecnologias no ensino fundamental. Programa de Pós-graduação em Geografia da Universidade Federal de Santa Maria. Dissertação de Mestrado (Mestrado em Geografia). Santa Maria, 2018.

SANTOS, R. L.; CARDOSO, D. L; BARBOSA, R. dos S. Princípios Básicos da Cartografia Escolar no Ensino Fundamental: Teoria e Prática. Revista de Ensino de Geografia, Uberlândia, v. 5, n. 8, p. 20-42, jan./jun. 2014. 